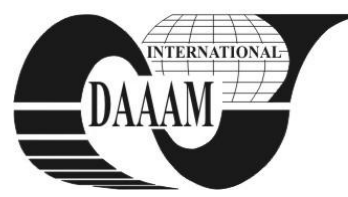

\title{
INCREASING OF OPERATIONAL RELIABILITY OF TECHNICAL SYSTEM
}

\author{
STRAKA, L[uboslav]; RIMAR, M[iroslav]; CORNY, I[van] \& MIHALCOVA, J[anka]
}

\begin{abstract}
The aim of the contribution is to describe reliability control in technical systems with focus on maximizing overall system reliability by the means of optimal selection of basic elements or by proper redundancy of the elements. The contribution shows an alternative of technical system reliability increase by the means of passive reliability increase of its parts. Further, possibilities of reliability increase by the means of active and passive reserve are described, as a higher level of reliability control in technical systems. In conclusion, summary of particular ways of reliability increase is presented on an example of a given technical system.
\end{abstract}

Key words: redundancy, reliability, technical system, reserving

\section{INTRODUCTION}

Requirement of maximum reliability in general means an effort to decrease failure intensity of particular elements of technical system. Thus, usually values of partial reliability indicators are improved, e. g. probability of survival, failure probability, failure rate, etc. The increase of technical system reliability can be achieved by increase of passive reliability of its components or by appropriate choice of reserve. . Reserving of the system, subsystem or particular elements is required only in the case when all technical possibilities for passive reliability increase are depleted (Straka, 2008).

However, system reserving has its practical limitations too. The range of reserving of elements or subsystems is influenced by variety of factors, some of which are significant, e. g. technical, physical, and economic obstacles. In addition, by an excessive increase of reserving elements number, system energy demand grows considerably, and in the same time, investment and operational costs grow non-proportionally to overall level of reliability increase.

\section{INCREASE OF PASSIVE RELIABILITY OF TECHNICAL SYSTEM}

The mean for reliability increase of technical system is an increase of passive reliability of its particular elements. Design proposal of any technical device usually takes into account minimal inevitable set of technical means that are needed to carry out required functions in a given range and quality. (Fabian \& Straka, 2008). It is not suitable to implement redundant or even useless elements into the system, the elements that would decrease reliability of the system as a whole.

In general, calculation of important reliability parameters is based on serial reliability model. In such case, reliability of technical system represented by the probability of survival $R(t)$ obeys following formula:

$$
R(t)=\prod_{i=1}^{n} R_{i}(t)
$$

where $R_{i}(t)$ is probability of survival of $i$-tuple element of the system in time $t$ from introduction of the system into operation.
Let's observe a simple technical system (Fig. 1) that consists of four essential parts (subsystems). We assume serial connection of subsystems with probability of survival of particular parts in time $t: R_{I}(t)=0.95, R_{2}(t)=0.97, R_{3}(t)=0.98$, and $R_{4}(t)=0.99$.

Subsystem 1
$R_{1}(t)=0.95$$\rightarrow \begin{aligned} & \text { Subsystem 2 } \\ & R_{2}(t)=0.97\end{aligned} \rightarrow \begin{aligned} & \text { Subsystem 3 } \\ & R_{3}(t)=0.98\end{aligned} \rightarrow \begin{aligned} & \text { Subsystem } 4 \\ & R_{4}(t)=0.99\end{aligned} \vec{Q}_{S}(t)$

Fig. 1. Serial reliability model of technical system

Required reliability of technical system in time $t$ from introduction into operation is $R s(t)=0.97$. However, reliability of the given technical system composed from the given four subsystems with known probabilities of survival determined by the formula (1) is in time $t$ insufficient:

$$
R s(t)=\prod_{i=1}^{n} R_{i}(t)=R_{1}(t) \cdot R_{2}(t) \cdot R_{3}(t) \cdot R_{4}(t)=0.894
$$

To achieve required reliability of the technical system $R s(t)=0.97$, it will be necessary to increase passive reliability of particular subsystems. However, the question is, whether higher effect will be achieved by reliability increase of all subsystems to a certain optimal level or by radical reliability increase of one of four subsystems.

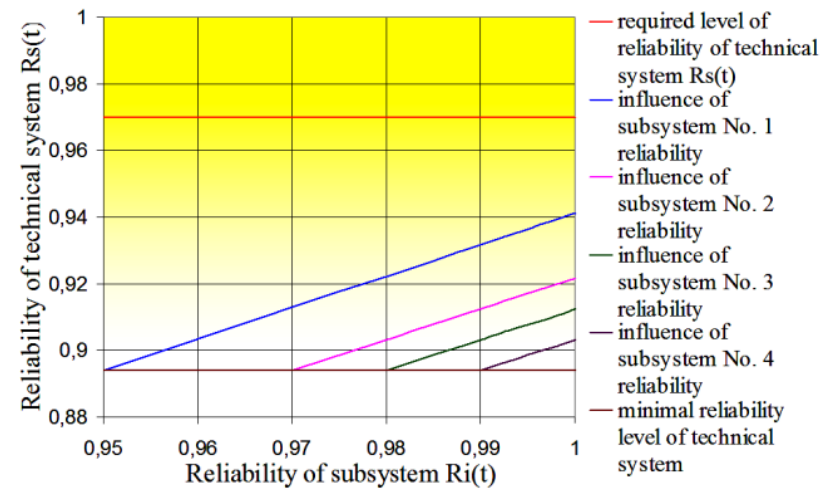

Fig. 2. The reliability course of given technical system

Graphical representation (Fig. 2) shows that the given technical system would not achieve required reliability $R s(t)=0.97$ only by unilateral radical increase of reliability of one part of the system, not even when subsystem's theoretical reliability $R_{i}(t)=1$ (reliability of $100 \%$ is virtually impossible in technical practice), (Panda \& Pandová, 2010).

Following apparent step is an increase of reliability of all subsystems. The question is, though, what is the minimal level of the reliability increase of partial elements to ensure required reliability of technical system in time t on the level $R s(t)=0.97$. 


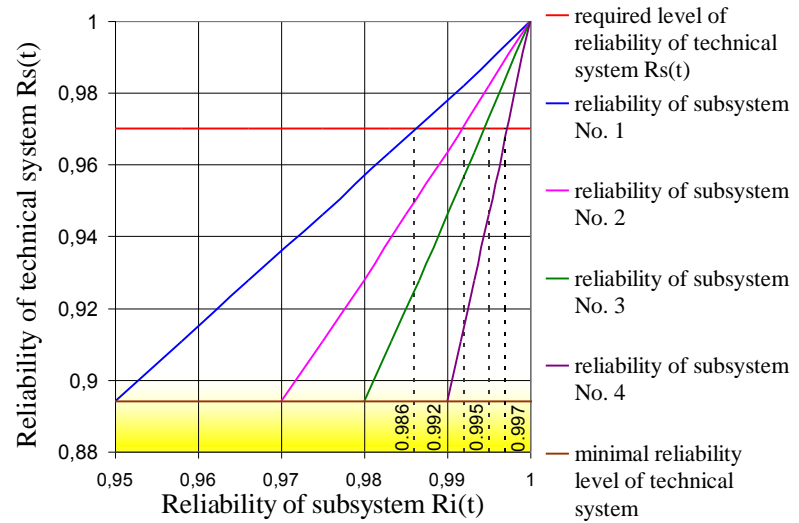

Fig. 3. Determining of reliability minimal level of partial elements of the technical system

Graphical representation on Fig. 3 shows minimal values of reliability of partial elements of technical system, so that total reliability of the system is reached on the level $R s(t)=0.97$. Minimal reliability level of subsystem No. 1 is $R_{l}(t)=0.986$, of subsystem No. 2 it is $R_{2}(t)=0.992$, of subsystem No. 3 it is $R_{3}(t)=0.995$, of subsystem No. 4 it is $R_{4}(t)=0.997$. By this combination we achieve required reliability of technical system $\operatorname{Rs}(\mathrm{t})=0.97$, this is confirmed also by calculation:

$$
R s(t)=\prod_{i=1}^{n} R_{i}(t)=R_{1}(t) \cdot R_{2}(t) \cdot R_{3}(t) \cdot R_{4}(t)=0.9703
$$

\section{INCREASE OF SYSTEM RELIABILITY BY RESERVING}

Reserving of the system is in general understood as increase of reliability by intentionally built-in redundant elements or subsystems. As a reserve is designated a mean, application of which would be useless if all elements of the system worked reliably, i. e. without failure. System reserving is generally applicable when all (mainly technical) possibilities for a passive reliability increase of system elements or subsystems are depleted (Fuchs, 2002). Application of a reserve in technical system is automatically reflected in an increase of system realization costs. Thus it is important to propose such a measure of redundancy in the system that responds to reliability requirements considering required operating life, readiness or safety of the system (Futó \& Bogdanovská, 2005).

To be able to make a qualified decision about a way of system reliability increase, we need to identify several important informations about the system. A significant task is an optimal selection of subsystem elements or selection of whole subsystems suitable for reserving. In the case of system reserving we are talking about so-called parallel reliability model. Probability of survival $R p(t)$ of this model is calculated by the formula:

$$
R_{p}(t)=1-\prod_{i=1}^{n}\left(1-R_{i}(t)\right)
$$

One possibility how to achieve required reliability $R s(t)=0.97$ of the observed technical system without an increase of passive reliability of particular subsystems, is the application of dynamic reserving of particular subsystems.

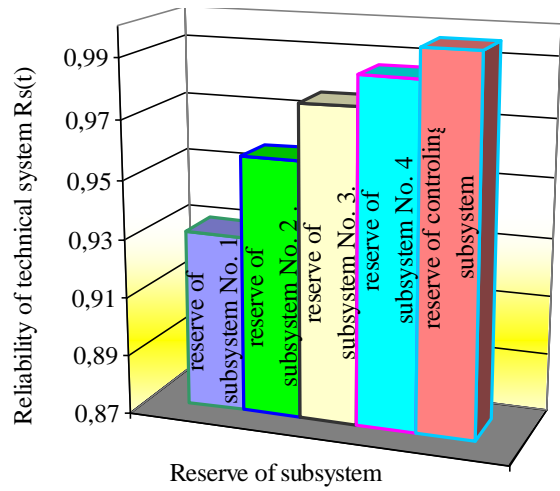

Fig. 4. Increase of reliability of technical system by dynamic reserving of particular subsystems
The graphical dependence demonstrates increase of reliability of technical system by the mean of reliability increase of particular subsystems by dynamic reserve. It describes reliability increase of the system by gradual reserving of particular basic subsystems. Reliability of the given system is in a certain extent negatively influenced by the controlswitching element. In spite of high reliability requirements on control-switching element, in practice $100 \%$ reliability of this element can not be achieved. In the given technical system, reliability of the control-switching element was proposed $\operatorname{Rpr}(t)=0.99$. The system has gradual dynamic reserving of particular subsystems. To achieve required reliability of the system $R s(t)=0.97$, it is necessary to implement dynamic reserves for first three subsystems as a minimum, which fact is confirmed by the following calculation:

$R_{s p}(t)=\left[1-\left(1-R_{1}(t)\right)^{2}\right] \cdot\left[1-\left(1-R_{2}(t)\right)^{2}\right] \cdot\left[1-\left(1-R_{3}(t)\right)^{2}\right] \cdot R_{4}(t) \cdot R_{p r}(t)$ $R_{s p}(t)=0,9975 \cdot 0,9991 \cdot 0,9996 \cdot 0,99 \cdot 0,99=0,976$

\section{CONCLUSION}

With a growing complexity of technical systems, reliability increase of the systems obtains growing significance. Since the system reliability depends on reliability of its parts (elements and subsystems), it is vital to eliminate weak points of the system. The importance dwells in decision whether it is more favourable to increase passive reliability of the system by increasing reliability of the weakest elements of the system, or to increase reliability of subsystems by reserving.

The aim of the contribution was to describe possibilities of increase of operating reliability of technical systems. To ensure required level of reliability of the given system, at first we took into account increase of passive reliability of system parts. Here, we often meet limit of technical possibilities of present practice, because reliability of particular elements depends on actual highest-possible achievable level of reliability of a given element. Wider possibilities concerning technical systems reliability increase are brought by reserving, where system reliability can be effectively increased even when reliability values of particular elements are relatively low. In reserving it is necessary to take into account whether system failure can or can not manifest itself outwardly. In the case the failure must not manifest itself, a relatively complex sequences of actions are necessary, the main task of these is a return of technical system from failure state into operable state. To carry out this task, control-switching element is needed. This element is also a negative part of the technical system since it brings a certain degree of unreliability into the system.

Increasing of reliability of particular components, as well as reserving, means certain increase of costs at technical system realization and operation. That is why it is necessary to propose such extent of system reserving which responds to required reliability level, operating life, readiness, and also safety. In spite of all the measures applied in design and operation phase, it is not possible to avoid some problems with optimal reliability level of technical system.

Note: The contribution was worked out with support of grant MŠ SR VEGA 1/0975/11 „Výskum metód real time multiparametrického monitoringu výrobných strojov a zariadení". (Research of real-time multi-parametric monitoring of manufacturing machines and facilities).

\section{REFERENCES}

Straka, L. (2008). Operating reliability in application examples, FVT TU in Košice with seat in Prešov, ISBN 978-80-553-0126-6, Prešov

Fabian, S. \& Straka, L. (2008). Operation of production systems, Edition of scientific literature, FVT TU in Košice with seat in Prešov, ISBN 978-80-8073-989-8, Prešov

Panda, A. \& Pandová, I. (2010). Evaluation systems and methods, FVT TU Košice, ISBN 978-80-553-0380, Prešov

Fuchs, P. (2002). Use of operational reliability in practice, Technical university in Liberec, Liberec

Futó, J. \& Bogdanovská, G. (2005). Reliability of Technical Systems, TU FBERG, ISBN 80-8073-357-0, Košice 